\title{
Industrias culturales y estética: un rastreo sobre su posible relación
}

\section{Carlos Andrés Arango-Lopera ${ }^{1}$}

Recibido: 2014-09-18

Enviado a pares: 2014-09-19
Aprobado por pares: 2014-11-12

Aceptado: 2014-12-02

DOI: 10.5294/pacla.2015.18.2.8

Para citar este artículo / To reference this article / Para citar este artigo Arango-Lopera, C.A. Junio de 2015. Industrias culturales y estética: un rastreo sobre su posible relación. Palabra Clave 18(2), 499-536. DOI: 10.5294/pacla.2015.18.2.8

\section{Resumen}

El presente trabajo elabora un recorrido por el concepto de industrias culturales desde la perspectiva estética. Es una reflexión que surge en el seno de la investigación "Estética cotidiana y literatura", que pretende abordar la lectura literaria desde la perspectiva de la estética cotidiana en el contexto de la formación de estudiantes de Comunicación y Lenguajes Audiovisuales, es decir, la formación de profesionales que van a generar y gestionar contenidos en la industrias culturales. Se siguió la metodología de la investigación documental, rastreando los principales aportes teóricos reseñados por los críticos en la materia. Al final, se aborda un campo de emergencias en el que se relacionan algunas inquietudes que surgen en el ejercicio y que alimentan la investigación posterior.

\section{Palabras clave}

Industrias culturales, estética cotidiana (Fuente: Tesauro de la Unesco).

1 Universidad de Medellín. caarango@udem.edu.co 


\section{Cultural Industries and Aesthetics: A Crawl on their Possible Relationship}

\section{Abstract}

This paper elaborates a journey through the concept of cultural industries from the aesthetic perspective. It is a reflection that arises within the research of "everyday esthetics and literature", which aims to address the literary reading from the perspective of everyday aesthetics in the context of training Communication and Audiovisual Languages students, i.e., training professionals who will generate and manage content in the Cultural Industries. A documentary research methodology was followed, tracking the major theoretical contributions reviewed by critics in the field. At the end discussion on the field of emergencies in which some concerns arose during the exercise and that fuels future research.

\section{Keywords}

Cultural Industries, Daily Aesthetics (Source: Unesco Thesaurus). 


\section{Indústrias culturais e estéticas: uma investigação sobre sua possível relação}

\section{Resumo}

O presente trabalho elabora um percorrido pelo conceito de Indústrias Culturais sob a perspectiva estética. É uma reflexão que surge no interior da pesquisa "Estética cotidiana e literatura", que pretende abordar a leitura literária a partir da estética cotidiana no contexto da formação de estudantes de Comunicação e Linguagens Audiovisuais, isto é, a formação de profissionais que gerarão e administrarão conteúdos nas Indústrias Culturais. Seguiu-se a metodologia da pesquisa documental, investigando as principais contribuições teóricas resenhadas pelos críticos na matéria. Ao final, aborda-se um campo de Emergências no qual se relacionam algumas inquietações que surgem no exercício e que alimentam a investigação posterior.

\section{Palavras-chave}

Indústrias culturais, estética cotidiana (Fonte: Tesauro da Unesco). 


\section{Introducción}

En el contexto de una investigación sobre la literatura como forma de aproximación a una estética de lo cotidiano proyectada en la formación de profesionales para las industrias culturales, este texto pretende revisar algunos aportes que diferentes autores y teorías han realizado en términos de cómo desde la industria cultural se lee la estética. Tan pronto surgió la necesidad de realizar dicha revisión, surgieron unos referentes bibliográficos fundamentales (e incluso fundantes) en relación con la conceptualización misma de la industria cultural, así como unas posiciones reconocidas en el ámbito de los estudios culturales, la sociología y los estudios de comunicación de masas respecto a una visión de sospecha sobre lo estético.

Nos referimos, en primer término, a la fundamentación que Adorno y Horkheimer realizan del concepto de industria cultural y que será objeto de la primera parte del texto. En segunda instancia, nos referimos a reconocidos autores como Baudrillard y Lipovetsky, en cuya obra reconocemos una crítica constante a lo estético como un gancho, como señuelo, para las masas. Ambos referentes son el acicate que empleamos para preguntarnos si más allá de esas posiciones radical y típicamente defendidas por estos autores existe la posibilidad de concebir alternativamente la estética. En términos concretos, preguntamos si más allá de acusar la inocencia de las masas ante los fulgurantes colores de la pantalla y los reiterativos sonidos de la canción radial, se ha concebido la posibilidad de que dentro de la industria cultural existan reflexiones e incluso experiencias que den lugar a pensar en la estética como algo más que adorno, señuelo o estrategia masificada de engaño.

Esta forma de plantear el interrogante de base genera entonces unos momentos que abordaremos en el texto. En primer lugar, las ideas principales que Adorno y Horkheimer contemplan para la configuración de su idea de industria cultural: qué entienden por ella y cuáles son las inferencias que en el marco de su reflexión los van llevando a su postura crítica. Luego, algunos autores que han continuado esta línea de pensamiento, donde aparecerán los ya mencionados Baudrillard y Lipovetsky, amén de otros autores que aun con diferentes posturas y marcos referenciales han continuado 
-de una u otra manera- esta forma de pensar frente a lo estético, y en especial a lo estético masificado.

El recorrido por los textos quedaría incompleto si no miráramos a quienes no se han vinculado del todo con dicha posición crítica, sino que han contemplado alternativas de conceptualización donde la masificación y la producción en serie no son agentes del mal, sino vías de hecho, espacios de configuración de fenómenos, los cuales se deben identificar, describir y caracterizar para comprender mejor el mundo contemporáneo. Al final del recorrido, apuntamos una serie de reflexiones, que señalan cómo la mirada esquemática con la que se asume el análisis de las industrias culturales, y dentro de ellas lo estético, amenaza con ser tan superficial como los contenidos mismos que analizan, pues suelen perder de vista ciertos aspectos que a la luz de nuestro marco comprensivo desconocen la posibilidad de lo estético como un aspecto vital en la comprensión del hombre y los grupos sociales de los que participa: "La filosofía no es un asunto meramente teórico, sino un asunto teórico-práctico: la filosofía -el pensamiento- ha de hacerse historia para cumplir su sentido, para reconciliar el derecho pendiente a la felicidad de sus víctimas" (Sánchez, 2009: 19).

Al final, más que de "conclusiones", hemos querido hablar de "emergencias", algo así como ideas para ayudar a entender ese cierto vacío que encontramos al mirar cómo la industria cultural mapea a la estética "simplemente" como aderezo y no como alguna otra cosa menos delgada.

\section{El comienzo}

El concepto de industria cultural surge en el seno del pensamiento crítico de Adorno y Horkheimer. ${ }^{2}$ El lugar donde los dos autores aportaron a la concepción de la industria cultural como la suma de los recorridos previos de ambos fue el texto Dialéctica de la Ilustración. Como lector, recorrer el texto va dejando la idea de que si por algo fue (y es aún) un libro de referencia, es porque recoge ideas de dos mentes distintas y que su tiempo de

2 Remitimos al lector, para efectos de contextualización, a los estudios de Axel Honeth y Noël Caroll, autores claros que nos aportaron bastante en la comprensión de este pensamiento, y que para efectos de este ejercicio complementamos con notas críticas, revisiones y referencias que autores de muchas inclinaciones teóricas y variedad de contextos históricos realizan. 
maduración coincide con una época de difíciles cambios para la humanidad. Ello se ve reflejado en el tono, a veces amargo, a veces escéptico, pero siempre muy inteligente, en el que está escrito.

Resaltamos, en primer lugar, el acento que los autores ponen en destruir la Ilustración como forma y como resultado, mas no como proyecto. De entrada, los autores advierten su propósito en el prólogo a la edición de 1944: "Lo que nos habíamos propuesto era nada menos que comprender por qué la humanidad, en lugar de entrar en un estado verdaderamente humano, se hunde en un nuevo género de barbarie" (p. 23). El camino de desviación de lo verdaderamente humano a la barbarie está marcado -es una de sus tesis más fuertes- en la génesis misma del proyecto, pues mientras la Ilustración proponía la razón como vía de acceso a la mayoría de edad (Kant), el camino que planteó fue la destrucción del pensamiento mítico, concepto en el que resuenan ecos de lo acaecido en la Grecia clásica, cuando Platón enfiló sus más agudos recursos a destruir los mitos por vía de la razón, episodio que quedó ilustrado para la historia en su mito de la caverna. Lo que acusan los autores es cómo la Ilustración, al plantear la necesidad de destruir el pensamiento mítico, lleva, por un lado, a la aspiración de dominar la naturaleza y, por otro, a la mitificación de la ciencia como única forma válida de configuración de la realidad.

$\mathrm{Al}$ efecto, afirman: "La Ilustración, en el más amplio sentido de pensamiento en continuo progreso, ha perseguido desde siempre el objetivo de liberar a los hombres del miedo y constituirlos en señores. Pero la tierra enteramente ilustrada resplandece bajo el signo de una triunfal calamidad. El programa de la Ilustración era el desencantamiento del mundo" (1948: 59). En este panorama, se desprende de lo que afirman los autores, el diseño del proyecto ilustrado fracasó en su concepción misma, pues a la postre la ciencia acabó con unos vínculos históricos que guardaban al hombre un lugar en el mundo. Desencadenado de estos vínculos, el hombre perdería noción de todo y de sí mismo, al punto de que la ciencia se le convirtió en la única manera de admitir las lecturas de la realidad.

La crítica a la Ilustración es el contexto en el que surge la industria cultural, pues según afirman en el mismo prólogo "la regresión de la Ilus- 
tración a ideología, que encuentra su expresión normativa en el cine y la radio. En este ámbito la Ilustración consiste en el cálculo de los efectos y en la técnica de producción y difusión; la ideología se agota, según su propio contenido, en la fetichización de lo existente y del poder que controla la técnica" (Adorno \& Horkheimer, 1948: 56). Como consecuencia, el mito es Ilustración y la Ilustración deviene mitología.

La forma como esto deviene una pérdida del vínculo con el mundo, se recoge en esta cita (p. 68):
A los hombres se les ha dado su sí mismo como suyo propio, distinto de todos los demás, para que con tanta mayor seguridad se convierta en igual. Pero dado que ese sí mismo no fue asimilado nunca del todo, la llustración simpatizó siempre con la coacción social, incluso durante el período liberal. La unidad del colectivo manipulado consis- te en la negación de cada individuo singular; es un sarcasmo para la sociedad que podría convertirlo realmente en un individuo. La hora, cuyo nombre reaparece sin duda en la organización de las juventudes hitlerianas, no es una recaída en la antigua barbarie, sino el triunfo de la igualdad represiva, la evolución de la igualdad ante el derecho hasta la negación del derecho mediante la igualdad.

Como consecuencia, se tiene un proyecto fracasado, que terminó siendo lo que combatió desde su génesis, y que dejó preparadas las condiciones para que el hombre se desconectara de los demás, y erigiera la individual como la esfera en la que realizaría sus más altos méritos. Pocas veces se señala que esta pérdida de vínculo sea la razón por la cual nace la industria cultural. Tal vez no sea la única razón, pero entendemos que sin esa pérdida de la idea de un colectivo, de unos vínculos con los demás, el concepto de masa no tendría sentido. Sabemos también que el pensamiento de ambos autores se refiere a la masa como un conjunto infinito de sujetos sin consciencia de sí, perdidos de toda noción de trascendencia.

El concepto mismo de industria cultural merecería todo un análisis completo. Aquí nos limitaremos, primero, a vincularlo con la denuncia del proyecto ilustrado vía la pérdida de vínculo, y por tal de razonamientos que lleven al hombre a elevar una mirada crítica sobre sí y sobre el mundo que habita. Si la Ilustración deviene la pérdida de encantamiento del mundo, lo 
que antes hacía ese encantamiento ahora lo ocuparán nuevos actores en el panorama. Se trata, desde luego, de los contenidos de la industria cultural, que ante la crisis de sentido que atraviesa el sujeto se convierte en lo único que -aparentemente- lo tiene.

La industria cultural recoge un sistema de producción y consumo codificado industrialmente de objetos estéticos serializados fabricados para ser difundidos masivamente y que requieren, por su conformación misma, un consumidor pasivo, que suele estar poco consciente de qué lugar ocupa en el mundo. Para los autores, la masificación del artefacto estético contrae sus posibilidades de sentido en el terreno del arte, y este queda supeditado a la categoría de mercancía. Es decir, los autores acusan la pérdida del valor artístico de los objetos a causa de su serialización, en lo cual asoman claros ecos de la pérdida del aura de la que hablara Benjamin. ${ }^{3}$

Asistimos a una dicotomía continente/contenido. Al estar cifrados en clave de la industrialización y la masificación, los objetos pierden contenido artístico. Por su parte, el continente de este nuevo tipo de objetos, los objetos estéticos, serán los medios masivos de comunicación: "Cine, radio y revistas constituyen un sistema. Cada sector está armonizado en sí mismo y todos entre ellos (...). La constitución del público, que en teoría y de hecho favorece al sistema de la industria cultural, es una parte del sistema, no su disculpa" (Horkheimer \& Adorno, 1998: 165). De suerte que la industria cultural es inconcebible sin el contenido (vacío de arte) de sus productos, y sin el encadenamiento de unas redes de comunicación que se encargan de masificarlos. Estos productos están planeados desde el comienzo para un tipo de consumo que no supone grandes esfuerzos racionales, y que apuntan mucho más a un conformismo de las personas frente al mundo en el que viven. Como consecuencia de este matrimonio, los autores advierten que la industria cultural es una rueda más entre las que integran un cierto orden en el mundo, que es el orden del capital. La industria

3 Adorno ha defendido esta idea de una escisión en su Teoría estética: "Tras la escisión del conocimiento en imagen y signo, el pensamiento identifica sin más la imagen escindida con la verdad; pero entonces no se justifica la falta de gravedad de la escisión, sino que se supera, pues afecta tanto a la imagen como al concepto. Como las imágenes no pueden traducirse a conceptos de forma perentoria, tampoco son 'reales'; no hay imagen sin algo imaginario; su realidad la tienen en su contenido histórico y no hay que hipostasiar las imágenes, ni aún las históricas” (pp. 118-119). 
cultural deviene un instrumento al servicio de unos intereses políticos de poder, dirigida a conservar el sistema y perpetuar sus valores como unos valores admitidos, válidos e incluso necesarios. Se trata de una táctica de domesticación de la masa.

Adviene con esto una serie de planteamientos críticos frente a la sociedad, pues la industria cultural apela a un tipo especial de racionalidad, a saber, la racionalidad técnica que es, en última instancia, la que domina el ámbito de la sociedad, llevando los contenidos y los contenedores de la sociedad a plantear un estado de cosas satisfactorio, a fin de que las personas no decidan asumir un papel activo frente al mundo.

Para los autores hay una misma línea de continuidad entre los totalitarismos europeos, que asumieron la ideología como una manera de cegar a las audiencias, y el capitalismo, que se encarga de difundir unos valores aparentemente legítimos mientras esconde tras la estética de los artefactos masificados sus verdaderas y crueles intenciones. La ideología surge como el contenido del capital. Un contenido, desde luego, fatuo.

La circunstancia misma de descreer del valor artístico de los contenidos estéticos y estetizados de la industria cultural surge en el marco de una distinción entre arte serio y arte ligero. Dicha distinción pasa por el contexto histórico. La guerra forja un estado de cosas en el que el arte, en especial el arte moderno, se convirtió en puerta hacia nuevos horizontes de sentido. En efecto, durante la guerra, el arte fue crítico, analítico, y estableció una postura no solo hostil sino marcadamente vital frente a los regímenes. $\mathrm{Si}$ los artistas terminaron siendo hostiles no fue tanto porque se lo propusieran, sino porque era la consecuencia misma de lo que estaban planteando en sus pinturas, su música y su literatura. Allí vemos un arte que deconstruye el mundo y explora nuevas capas de significado dentro y fuera de él. Eso fueron las vanguardias: una zona de exploración, por vía estética, del sentido vital de vivir, a la vez que un reclamo al absurdo (humano) de la guerra.

Frente a este estatuto artístico, los autores de la Dialéctica de la Ilustración denuncian una masificación de productos culturales que los hace más 
livianos, complacientes y, podríamos decir, pasteurizados frente al mundo. Se trata de un arte ligero, en el que la técnica obedece a la demanda industrial de producción en serie y no a una exploración del objeto artístico mismo. Es decir, mientras el artista moderno y de vanguardia encuentra en la técnica un auxilio de su visión del mundo, en la industria cultural la técnica, heredera de la razón técnica y tecnificada, hija de la racionalidad del capital, aplasta al objeto del arte y lo constriñe a mera forma de un mensaje vacío.

Encontramos en esto último un punto de inflexión del pensamiento referido a la estética en el seno de la industria cultural, porque en adelante muchos serán los críticos (y muy fuertes sus palabras) que asimilarán la separación entre un arte ligero y un arte verdadero, un arte legítimo y uno ilegítimo; en otras palabras, entre arte y basura mediática.

\section{Las posturas críticas (apocalipsis estético)}

Herederos del pensamiento de posguerra, de una tradición en la que ser intelectual es ser intelectual comprometido, e intelectual comprometido implica, sí o sí, una cierta animadversión frente al establecimiento; donde pensar es, necesariamente, pensar escépticamente, encontramos aquí una serie de autores para quienes la sociedad de masas es un escenario de dominación ideológica, manipulado por las esferas de poder, a quienes no les interesa un sujeto crítico, racional o mínimamente informado. Estos autores son asumidos dentro de nuestra descripción como continuadores del legado de Adorno y Horkheimer, y se verá en ellos que, a menudo, no se salen de la idea de un arte superior $y$ un arte inferior, en tanto dudan muy poco sobre su convicción de que masificado implica fofo, inaportante y enajenador. Los reunimos acá para señalar que en su mayoría, aunque con matices y particularidades, adscriben una visión de lo estético donde lo agradable no solo se usa como señuelo, sino que no podría ser otra cosa. Es decir, queda entre líneas la idea de que la sociedad de consumo está configurada en clave estética porque difícilmente se podría tener una visión de lo estético como un asunto profundamente vital.

Comenzamos el recorrido con Jean Baudrillard, y con esta elección no apuntamos tanto a una razón cronológica ni epistemológica como a una 
en la que el sentido de las ideas planteadas por Adorno y Horkheimer en la Dialéctica de la Ilustración cobran un nuevo nivel. Afines los tres autores al pensamiento marxista, encontramos en Baudrillard una serie de ejercicios que apuntan a deconstruir la lógica con la que está armada la sociedad que le tocó vivir. Los asuntos del valor, el capital, la ideología y otros que ya aparecían en la Dialéctica vuelven a aparecer aquí convocados en auxilio de una teoría del consumo. En efecto, Baudrillard comenzó su vida de intelectual publicando tres libros que se entienden como un tríptico, en la medida en que cada uno lleva a diferentes niveles el análisis de la sociedad estudiada por el autor.

Se advierte claramente en el pensamiento del sociólogo francés que la sociedad requiere una mirada crítica en la que nos podamos percatar de unas estructuras por donde se distribuyen unas determinadas relaciones de poder. De cierta manera, la primera parte de la obra de este pensador es una tríada en el sentido peirceano del asunto, en tanto que analiza una primeridad, que sería el objeto, los objetos; una segundidad, que sería la sociedad de consumo, como estructura operante de esa primeridad, y una terceridad, que sería la economía política del signo, es decir, una terceridad en toda su apoteosis abstracta: la entidad sígnica, en este caso.

En El sistema de los objetos, Baudrillard analiza cómo en la sociedad actual los objetos no se clasifican por ser su condición misma de objetos, sino más por el uso y el valor que se les da. El texto propone entonces una guía de cómo los objetos han cambiado su comportamiento frente a los estilos de vida, la clase social, los colores y otros órdenes de clasificación que superan lo funcional.

Allí, un apartado le dedica Baudrillard al objeto coleccionado, del que dice es el perfecto animal doméstico, pues responde a su amo, engrandece sus cualidades, se hace parte de él, y no erige necesidades ajenas a las que el dueño le exige; está por entero a su disposición, sin requerimientos, ni exigencias notables. Se deduce de las argumentaciones del autor que esta relación amo-esclavo a la que se ven llevados los objetos guarda relación con la publicidad, un dominio discursivo que integra (construye) la semánti- 
ca misma del objeto y prefigura su gramática. Es decir, la publicidad dicta el significado de los objetos, lo prefabrica antes de que lleguen a manos de sus usuarios, mientras establece el dominio de la vida cotidiana a donde llegará. Esta relación semántica y gramatical, dice, es novedosa y se consolida gracias a la sociedad industrial, donde la publicidad asoma como un espacio de indexación de los objetos. La publicidad, si bien no entra en ningún proceso funcional, se vuelve parte del objeto mismo desde su discurso. Pero se trata de una lógica de lo inesencial, una apología del consumo por el consumo mismo. Al mismo tiempo, la publicidad deviene una proclamación de la capacidad de compra de las personas, pues en su retórica se apela al lugar que ocupan quienes adquieren los productos por ella anunciados: "Una de las primeras reivindicaciones del hombre, en su acceso al bienestar, es la de los que se ocupen de sus deseos, de formularlos, y de dotarlos de imágenes ante sus ojos (esto llega a ser un problema en un país socialista). La publicidad cumple la función útil, regresiva, inesencial, pero profundamente requerida" (2004: 198).

De esta forma, los objetos son una forma tangible de una experiencia estética, en tanto que todos los sentidos se ven convocados a ella. Desde el uso que se le da al objeto, la experiencia generada centra su punto de gravedad en lo estético, movimiento que comienza en la publicidad con que se anuncia el producto, y continúa en el momento en el que se le da un valor, o un uso diferente al que se le destinó a ese objeto, es decir, una apropiación.

En La sociedad de consumo, Baudrillard amplía la mirada y deja de pensar solo en el objeto para darle cabida a la sociedad en la que ese tipo de transacciones (estéticas, funcionales y no solo económicas, impulsadas por el discurso publicitario) con los objetos es posible. Allí, encuentra un tipo de sociedad en la que el consumo es una estancia que va más allá del uso de unos bienes para la satisfacción de necesidades, y encuentra cosas como que el éxito social, la felicidad individual y otras situaciones similares están claramente relacionadas con lo que se consume y, sobre todo, con lo que se ostenta. Uno de esos valores enaltecidos por este tipo de sociedad es el confort: "El hecho de que la felicidad tenga ante toda esta significación y esta función ideológica induce consecuencias importantes en lo que a su 
contenido se refiere: para ser el vehículo del mito igualitario, es necesario que la felicidad sea mensurable. Es preciso que se trate del bienestar mensurable por objetos y signos, del confort (...)” (1970: 77).

Así, en la medida en que el individuo se encuentra rodeado de mensajes que le hablan de objetos, la publicidad consolida la idea de que la abundancia, la panoplia, la colección integran el estado natural de las cosas. Allí, el autor señala las droguerías y los supermercados como los escenarios que la sociedad de consumo requiere para perpetuar su idea de que el estatus social viene condicionado por lo que se consume, lo cual solo es verificable por vía de la ostentación de los bienes adquiridos y la exhibición de su compra. En virtud de este proceso, la relación del consumidor con el mundo real, con la política, la historia, la cultura, no es precisamente una praxis de interés pero tampoco de indiferencia total; es más bien una relación de curiosidad y desconocimiento. El lugar del consumo, la vida cotidiana, con su banalidad y repetición, se convierte en un sistema de interpretaciones, en el que se da una constante relación dialéctica entre la esfera transcendente, autónoma y abstracta de lo público y la esfera inmanente, cerrada y abstracta de lo privado.

El consumo transforma la exclusión mutua de estas dos esferas, reduciendo al máximo las tensiones, apuntando a una felicidad que intenta a toda costa disimular cualquier sentimiento de culpa por la pasividad con la que el consumidor se expone a toda esta espectacularización de la realidad. El consumo le muestra al individuo-consumidor una latente catástrofe cercana a él, donde esta supuesta violencia y carácter inhumano de la esfera pública justifica el deseo de protección y seguridad que el consumo estará presto a brindarle; la cotidianidad se llena de miedo, penumbra y tragedia.

La teoría del consumo de Baudrillard parte de la idea de que el consumo se mueve a través de varias lógicas. Una de ellas es la "ideología igualitaria del bienestar", que lleva consigo un discurso basado en las necesidades y la propensión de los seres humanos por la búsqueda de la felicidad; así, todos los individuos somos iguales ante la necesidad y ante el principio de satisfacción, ya que somos iguales en el valor de uso de los objetos pero desiguales ante el valor de intercambio. 
En Baudrillard asistimos a una crítica que pretende reconocer las estructuras de intercambio simbólico que hay en la sociedad de consumo. Como vemos, su reflexión en lo estético no es particularmente aguda, y se enfoca más en considerar la estética como una dimensión que se reconoce fácil en la relación que las personas adquieren con los objetos, en la forma de comunicación que establece la publicidad y en la forma como todo el sistema de objetos y consumo gira en torno a la ostentación de estos bienes para obtener un lugar en el grupo social.

Así, con Baudrillard aparece algo que no estaba totalmente definido en el ámbito teórico: la idea de que el consumo es un hecho social; en palabras de Alonso, "El consumo es un hecho social total -una producción simbólica: depende de los sentidos y valores que los grupos sociales dan a los objetos y las actividades de consumo" (2005: 30). En este sentido, vale apuntar que las teorías del consumo que siguieron las reflexiones de Baudrillard van a continuar la idea de que en el consumo se asiste a un proceso de intercambio simbólico, donde las dimensiones estética, simbólica y sociológica de los bienes deviene algo más importante que la dimensión funcional y económica desde la que tradicionalmente se había pensado el asunto.

La categoría de la sociedad de consumo será la que permitirá entender una serie de macroprocesos sociales que, en adelante, se realizan en clave de consumo, pues se basan en la oferta seductora de bienes y su consumo sensual: de esta manera, mientras lo público va perdiendo el interés generalizado de las personas, el consumo (privado) se va convirtiendo en un lugar cada vez más interesante de vivir: "Por miedo a la violencia o por búsqueda de prestigio y distinción, los residentes de nivel socioeconómico medio $y$ alto eligen vivir en el fraccionamiento cerrado sin importar si los espacios se integran o no a la estructura urbana” (Enríquez, 2007: 27).

Otro autor relevante que se ubica en esta línea es Lipovetsky. El pensador francés se ha caracterizado por una escritura apocalíptica, que no ha titubeado al momento de señalar cuán vacía, infeliz y superflua es la sociedad actual. Como veremos, también en Lipovetsky lo estético es aquello que se encuentra en la superficie y se coloca como señuelo para el otro. 
Pero, además, este autor denuncia claramente que el camino del placer es el opuesto al del deber, y no ha dudado en mostrar en qué consiste llevar al extremo (a lo hiper) este modo de ser.

En La era del vacío (1986), Lipovetsky afirma que todo el esfuerzo social está ahora dirigido a un placer privado, que atiende necesidades particulares para seducir, con el fin de consumir; la coerción y la represión en la cual las personas anteriormente vivían, y las costumbres a las cuales se tenían que adaptar, han sido modificadas, de manera que las instituciones se han acoplado a las motivaciones personales seduciendo, brindando y personalizando los bienes para que cada quien escoja a la carta lo que quiere para su vida. Así, la seducción se ha convertido en el proceso central de regulación del consumo, las organizaciones, la información, la educación y las costumbres. Como consecuencia, sobreviene un mar de desinterés hacia las instituciones que otrora rigieron, pues ahora se encuentran vaciadas de su sustancia.

Una de las figuras centrales de este proceso es, hoy, Narciso. Narciso es el símbolo de nuestro tiempo: "Narciso colectivo: nos juntamos porque nos parecemos, porque estamos directamente sensibilizados por los mismos objetos existenciales" (p. 14), pues somos seres absortos en la contemplación de nuestra propia belleza; o mejor, de nuestro propio placer infinito.

Un rasgo particular de esta concepción es que el cuerpo asoma como el escenario más importante de la sociedad de consumo. Los productos, los servicios y las estrategias sociales se dirigen a él. A su cuidado, a su contemplación. En La tercera mujer (2007), concluye que en el cuerpo y la forma en que se procura su mantenimiento ocurren los móviles cada vez más importantes de las pasiones y la energía contemporánea. El mundo mismo es, hoy, bastante femenino, en la medida en que la delicadeza, la vanidad y el cuidado son valores céntricos en la vida de los hombres y las mujeres. Valores como la antiedad, el antipeso, el bronceo, la alimentación balanceada y una serie de técnicas de cuidado del yo se abren a todas las clases sociales, de forma que se establecen como universales. 
De especial interés para nuestra pregunta orientadora es constatar que toda esta transformación en los rituales de contemplación y cuidado de la cultura física trajo consigo una transformación radical en las formas de pensar el ser hombre y el ser mujer: la mujer se permitió liberarse de opresiones sociales, políticas, económicas y morales, aspirar a las mismas posibilidades de educación superior, competir en el mundo laboral y cuestionar su lugar como ama de casa. Es decir, una serie de transformaciones sociales hicieron que, finalmente, lo estético se asociara con lo femenino, muy de la mano de lo que sucedió en la modernidad, donde la mujer no figuró en el espacio público, pero se hizo acreedora a un sinnúmero de asociaciones simbólicas relacionadas con lo íntimo y lo privado, siempre de la mano de lo sexual y con un pago enorme por vía de la vida doméstica.

En la búsqueda interminable del placer, Lipovetsky basa la razón por la cual la vida social contemporánea es vacía. Las instituciones carecen de alma, pues se han volcado ya no al control de la subjetividad, sino a su complacencia; la mujer se ha desfigurado, porque ha entrado a atender nuevas demandas de autorrealización basadas en la contemplación del cuerpo. Así, en El imperio de lo efímero (2009), las tesis que expone apuntan a establecer que el código comunicacional de la sociedad contemporánea es la moda, y con ella todo el culto a la novedad. El texto se estructura como una reflexión que supera el análisis tradicional de la diferencia entre clases, para entender la moda como un componente de carácter libertario, convertido ya en signo de transformación:

el devenir moda de nuestras sociedades se identifica con la institucionalización del consumo, la creación a gran escala de necesidades artificiales y la normalización e hipercontrol de la vida privada. La sociedad de consumo supone programación de lo cotidiano; manipula y cuadricula racionalmente la vida individual y social en todos sus intersticios; todo se transforma en artificio e ilusión al servicio del beneficio capitalista y de las clases dominantes (p. 126).

A través de la lectura que el autor realiza de la moda, esta va surgiendo como elemento transversal en las dinámicas de transformación de la sociedad moderna. El resultado de la centralización de la moda como aspecto vital en la vida es que ella va mediando unos aspectos donde lo efímero, lo 
nuevo y lo banal devienen protagonistas del modo de ser contemporáneo, con lo cual algo mucho más profundo se ha transformado: de la necesidad social y política de estabilidad, certidumbre y rutina, la moda nos vallevando a un estado de cosas donde la sorpresa, la novedad y la ruptura son las principales búsquedas: "La tendencia a la personalización de los productos y servicios se manifiesta en una economía en la que se impone la innovación sobre la producción” (2007, p.78).

Mas el inconveniente con la seducción de la moda y la sociedad de consumo no es la seducción misma, sino el establecimiento de la fascinación como el único camino posible para el desarrollo de la vida social. Advierte Marina (2007):

\begin{abstract}
El sistema del deseo tiene un aire seductor -la seducción es una de sus armas- y todos estamos dispuestos a caer bajo sus encantos. Es verdad que luego nos asustan algunas disfunciones sociales -la violencia, la depresión, la desconfianza generalizada, la fragilidad de los sentimientos, la corrupción, el abuso de poder-, pero no las relacionamos con el sistema invisible (p. 30).
\end{abstract}

Los apuntes de Lipovetsky llevan a establecer la idea de que el consumo es una institución social cuya lógica atraviesa las demás instituciones sociales, pues se convierte en un regulador de estas. Conviene insistir, entonces, que se trata de una transversalización de la estética, entendida como promesa instantánea, enormemente satisfactoria, de placer. Esas promesas publicitarias de placer inmediato, sin embargo, tienen un enorme costo social, pues ni la novedad de la moda nos hace más curiosos, ni la abundancia de las mercancías nos hace más felices, ni volcarnos a la seducción social nos permite ser más sensatos. Lo que sí aparece claramente es un consumidor más emocional, más atado al presente y más necesitado de emociones diarias, porque el ritmo intenso de la vida lo hace negativamente sensible a la monotonía: "La verdad es que existe un vínculo íntimo, estructural entre el hiperconsumo y hedonismo: ese vínculo es el cambio y la novedad" (Lipovetsky, 2007: 61).

Sumando, se tiene una sociedad llevada al inmediatismo espectacular del placer, pero donde las cosas se vacían de sentido: 
El consumo es superficial, vuelve infantiles a las masas; el rock es violento, no verbal, acaba con la razón; las industrias culturales están estereotipadas, la televisión embrutece a los individuos y fabrica moluscos descerebrados. El feeling y el zapping vacían las cabezas, el mal, en todas sus formas, es lo superficial, sin que ni por un segundo se llegue a sospechar que los efectos individuales y sociales contrarios a las apariencias puedan ser la verdad histórica de la era de la seducción generalizada (Lipovetsky, 2009: 8).

En Baudrillard y Lipovetsky ciframos los más notables aportes a una teoría reflexiva, crítica, posmarxista y, desde luego, escéptica, sobre la sociedad actual. El consumo, llevado a su nivel hiper, promueve un mundo atado al presente, envuelto en la dinámica del presente, insaciable en cuanto a las novedades, $y$, por eso mismo, vacío de sentido. Como hemos mostrado, la estética se asume como la parte notable, visible, llamativa y siempre amable del consumo.

Se pueden sintetizar estos aportes bajo la idea de que la industria cultural ofrece lo estético como gancho, superficie; canto de sirenas. La desconfianza por lo bello ya estaba presente en episodios anteriores de la humanidad, y desde la Grecia clásica se asocia a la belleza ilegítima con ilusión, en el sentido negativo del concepto, es decir, como engaño. Los críticos de la industria cultural denuncian permanentemente que lo bello, lo rimbombante y lo espectacular son los ganchos que utiliza la sociedad mediática para dejar que las audiencias se pierdan, masificadas, en el placer inmediato que proveen los medios. Allí, desde luego, proponemos que no solo la belleza, lo llamativo y lo placentero pertenecen como categorías a la estética. Sin embargo, entrar un poco en qué es lo que dice, y cuál es el juego de supuestos y afirmaciones que tejen esta red de sentido de estos autores, es necesario para comprender mejor su mirada.

Como hemos dicho, esta dicotomía entre lo racional y lo emocional, lo sensato y lo inmediato, lo puro y lo contaminado se da de cara al pensamiento moderno. Maffesoli denuncia una

dicotomía que la modernidad estableció entre la razón y lo imaginario, 0 entre la razón y lo sensible. En este sentido he hablado de "hiperracionalidad", es decir, de un modo de conocimiento que sepa 
integrar todos los parámetros que habitualmente se consideran secundarios: Io frívolo, la emoción, las apariencias... que se pueden resumir en la palabra "estética". Se podría hablar de "sensibilidad de la razón", a saber, aquello que en todos los campos: políticos, profesionales, morales, hace que la razón se estremezca en virtud de esas fuerzas sensibles de la vida privada o pública (2007: 11).

La dicotomía, clara, se alimenta del miedo que desde siempre las sociedades han manifestado por lo bello, lo atractivo, lo seductor, pues, en conjunto, son situaciones que plantean la disolución social, la desfiguración del grupo social, por medio del placer hedonista que centra al individuo en su esfera plenamente orgánica y lo deshabilita para la razón y el cumplimiento del deber:

Siempre se han experimentado deseos y, posiblemente, en épocas
pasadas se manifestaron de manera más feroz y menos controlada
que ahora (...). Pero las sociedades sintieron un permanente recelo
ante la proliferación de ansias, codicias y concupiscencias, porque
consideraban que eran un peligro para la cohesión social. El deseo
es, además, la antesala del placer, que también era mirado con in-
quina y desconfianza. Ahora, en cambio, y eso es lo novedoso, el
deseo está bien considerado, y hemos organizado una forma de vida
montada sobre su excitación continuada y un hedonismo asumible.
No vivimos en la orgía, sino en el catálogo publicitario de la orgía, es
decir, en la apetencia programada. La publicidad ya no da a conocer
los atractivos de un producto. Su función es producir sujetos desean-
tes (Marina, 2007, p. 13).

Absorto en la contemplación de lo bello, el individuo poco espacio dejará para pensar en su condición política, en su dimensión productivacreativa, o en su compromiso civil. De siempre, los placeres han amenazado con la provocación del desorden social, y por eso en las más variadas mitologías aparecen referencias al espacio ordenado en pugna constante con el espacio caótico, narraciones dicotómicas desde sus mismos temas: Sodoma y Gomorra, Caín y Abel (en estos dos casos enfatizamos la "y"), y en cuentos infantiles como "Los tres cerditos", donde, al fin, el cerdito que logra conservar en pie su casa es aquel que atiende el deber y desatiende la inmediatez de la pereza que llamaría siempre al descanso. 
De ahí que haya una crítica constante por parte de los pensadores sobre el entretenimiento, una esfera de comunicación que llama al placer por entero. Y también que acusen de la mixtura que conforma la sociedad espectacular, donde todo lo que aparece en la pantalla está permeado por esta lógica, trátese de un anuncio comercial, el noticiero de la noche o una eucaristía transmitida por la pantalla chica. En la conceptualización misma de la sociedad del entretenimiento vemos cómo asoma la sospecha de que entregarse al placer está, en sí mismo, mal visto. El entre-tenerse amenaza la posibilidad de autocrítica y cumplimiento del deber, pues el principio del placer concentra al individuo en una esfera donde no debe salir de sí mismo, absorto como está en las señales complacientes en las que lo envuelve su cuerpo. Parece pues que la narrativa surge como uno de los espacios donde la sociedad masiva logra enajenar al individuo, pues "la cultura mediática tiene un carácter esencialmente narrativo” (Martínez \& Gómez, 2007: 127).

De ahí que las generalizaciones asoman tan pronto los autores advierten la presencia de estados de apertura al placer. Al decir de Lipovetsky, asistimos a una época en la que el deber ya no nos convoca, pues la sociedad de consumo nos satisface teniéndonos siempre listo y disponible a nuestro pago inmediato (a un solo clic, pagando con la tarjeta de crédito o solo marcando un código en el celular) un inmenso catálogo de bienes para sumir en ellos nuestros placeres. De ahí que aparezcan los títulos generalistas del tipo La sociedad del espectáculo, La era del vacío, La sociedad de consumo y un considerable etcétera que nos señala claramente la línea de pensamiento en la que toda la sociedad ha caído en el placer infinito y ya no culpabilizado de regodearse en los deseos.

La estética inunda todo de placer (por medio de la narrativa o el impacto de las imágenes, por ejemplo), y con ello logra que las personas se entreguen a la pantalla sin ser capaces de ver nada más que lo que allí aparece. La sociedad del espectáculo opera igual que la sociedad de consumo, pues centra su estrategia de comunicación en las emociones, buscando desculpabilizar el deseo y anular el deber.

Así, diríamos, como continuación de la dicotomía contenido/continente, que la sociedad del espectáculo centra su crítica en los medios ma- 
sivos como agentes del entretenimiento, mientras la sociedad de consumo la centra en los objetos. Quiere esto decir que el contenido de los medios es el espectáculo, que se ofrece como mercancía, de manera que se configura un matrimonio entre los contenidos y los continentes: las mercancías se venden espectacularmente, los contenidos del entretenimiento se comunican publicitariamente. En esta burbuja, abundan los "Centros comerciales que se convierten en centros turísticos, que se transforman en parques temáticos que mutan hacia espacios de entretenimiento, y que acaban como espectáculos simulados" (Alonso, 2005: 111).

El espectáculo es el modo como se construyen los mensajes, con lo cual se logra que no consigamos distinguir entre lo que es real y lo que no lo es. Tanta información también va dejando una idea de que todo da igual, de que, haga lo que haga, el individuo no podrá cambiar lo que las noticias noche tras noche nos ratifican.

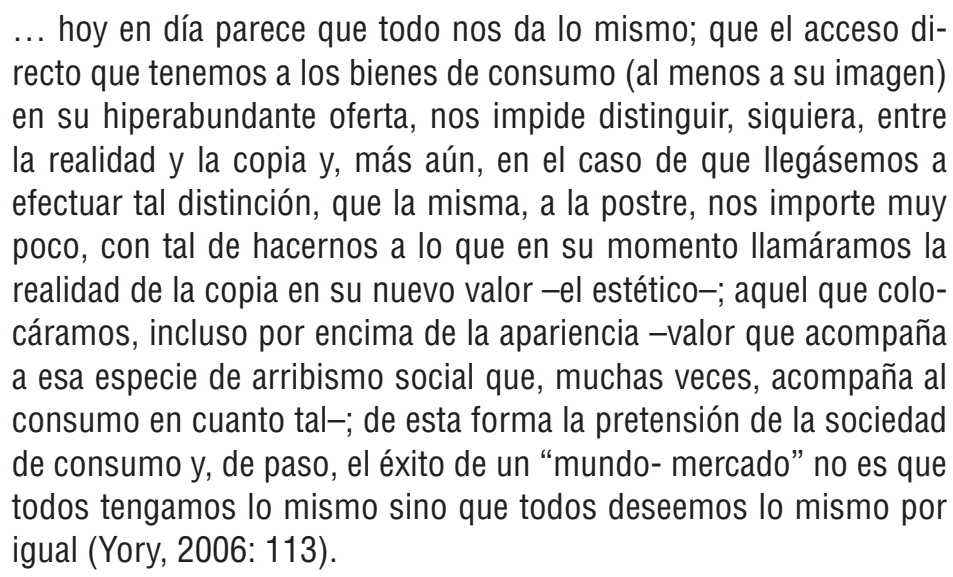

En el mismo sentido, Gil Calvo (2003) apunta que los medios, a través de la estrategia de contenidos de espectáculo, van logrando crear una cultura de la expectación, donde la relación con lo otro no se da desde lo racional, sino desde el ritual mismo de estar expectante. Las noticias, los debates políticos, todo, sin importar de qué se trata, se envuelve en la lógica del espectáculo, y de ello no se salvan ni los gobernantes televisivos ni los telepredicadores, todos buscando la manera de generar audiencias, medidas por el rating. Así las cosas, lo estético funge muy bien como el gancho 
que no permite a la gente salirse de lo entretenido que le resulta el mensaje, y no encuentra manera alguna -ni siquiera se le ocurre- de voltear la mirada y preguntarse con el otro si eso que están viendo será o no real, y si frente a eso cabrá o no alternativa alguna. La televisión logra convertir al otro en consumidor, y una vez envuelto en esta lógica, la idea de ciudadano político desaparece porque el entretenimiento existe para evitar las preocupaciones.

Lipovetsky señala que algo pasó socialmente para que las celebridades de la pantalla nos fueran deseables: "Para que se diera el auge de las frivolidades fue precisa una revolución en la imagen de las personas y en la propia conciencia, conmoción de las mentalidades y valores tradicionales; fue preciso que se ligaran la exaltación de la unicidad de los seres y su complemento, la promoción social de los signos de la diferencia personal” (2009: 43). En la forma de exhibición de esos signos estaría la estética, como estrategia de embellecimiento, y como consecuencia tenemos el modus operandi de la sociedad del espectáculo. En ella, afirma Debord, el espectáculo es una forma de relación social, en tanto que "no es un conjunto de imágenes sino una relación social entre las personas mediatizada por las imágenes" (1978: 38).

Esta relación social apunta al desprendimiento del hombre y la naturaleza acusado por Adorno y Horkheimer, pues el desencantamiento del mundo llevaría a una situación en la que el espectáculo es posible y eficaz para los intereses del establecimiento, en tanto genera una relación de intercambio. El entretenimiento solo es posible, en las dimensiones a las que asistimos contemporáneamente, en un mundo donde evitar el aburrimiento es una de las premisas mayores. La idea misma de la estética cotidiana rescata que en el correr diario de las horas, los días, los meses y los años, ocurren un montón de fenómenos que, de alguna manera, pasan inadvertidos para las personas, pero que recogen un enorme potencial de construcción de sentido. No así, la teoría ha ignorado sistemáticamente este poder; pero dicha ignorancia es bastante mayor en el seno de la línea teórica crítica, donde no se ha querido reconocer este potencial de lo cotidiano. Que el hombre promedio lo ignore y prefiera entretenerse es apenas comprensible, pero que la teoría haya aplastado a este individuo, teóricamente hablando, y haya su- 
puesto que en su hogar solo hay un televisor del que este jamás despega su mirada es casi un atrevimiento.

El espectáculo es una permanente guerra de opio cuyo objetivo es
conseguir la aceptación de la identificación entre bienes y mercan-
cías, así como entre la satisfacción de necesidades y la supervivencia
ampliada según las leyes de la mercancía (...). La vida entera de las
sociedades en las que imperan las condiciones de producción mo-
dernas se anuncia como una inmensa acumulación de espectáculos.
Todo directamente experimentado se ha convertido en una represen-
tación (Debord, 1978: 37 ).

Caro a las vanguardias, Debord extiende la idea de Adorno y Horkheimer de que hay un arte valioso y que la cultura de masas lejos está de producir algo que valga la pena. Para ello, Debord hace una exposición de las vanguardias juveniles de los sesenta, y muestra cómo el inconformismo de los jóvenes los llevó a búsquedas espirituales donde el arte surgió como vehículo de búsqueda y ruptura. Vemos entonces que de nuevo el asunto estético está vinculado al arte, y que todas las valoraciones estéticas se hacen en función de un canon que establece las diferencias claras entre un arte que vale la pena y un arte ligero. Este último, empleado por las sociedades de control para mantener controlado al sujeto. En efecto, para Vargas Llosa:

La literatura light, como el cine light y el arte light, da la impresión cómoda al lector y al espectador de ser culto, revolucionario, moderno, y de estar a la vanguardia, con un mínimo de esfuerzo intelectual. De este modo, esa cultura que se pretende avanzada y rupturista, en verdad propaga el conformismo a través de sus manifestaciones peores: la complacencia y la autosatisfación (2012: 37).

Allí vemos que el estudio que hacen los críticos de la sociedad del espectáculo se mueve en un eje de valoración donde hay una gran cultura, un acervo gigante lleno de experiencias valiosas, conceptos profundos y teorías razonables, que son el gran legado de la cultura occidental, y que la sociedad del espectáculo amenaza con exterminar.

Vemos pues que la estética aparece como el garante de una transición entre esa época dorada de ilustración y civilización, obediente del deber, 
democrática, crítica, basada en el logos como único posibilitador de sentido, y un estado de cosas donde ya nada importa, y la esfera individual es el único escenario de proyectos. Esto se debe fundamentalmente al hecho de que el centro de esta sociedad del espectáculo son las pantallas. Primero el cine, luego la televisión, ahora las pantallas digitales (celulares, computadores, tabletas...), todo un repertorio de dispositivos que fungen como los grilletes de esa nueva esclavitud, conformada por un grupo inmenso de personas consumiendo contenidos, y que se convierten en la razón (en sentido matemático) sobre la que se mide todo en la sociedad del espectáculo: la audiencia. En efecto, cada una de las personas que está consumiendo los contenidos es un aporte a los ratings y los estudios de audiencia que definen hoy quién es quién (en número de seguidores, suscriptores, contactos, puntos de rating, etcétera).

Con la capacidad narrativa generada por el lenguaje audiovisual que desarrolló el cine, más la portabilidad y la permanencia constante y ritualizada de la televisión, las pantallas se multiplican, y con ellas la cantidad de procesos sociales que se vuelcan a ellas y que, cada vez, se hacen menos posibles sin el tipo de visualidades que estas generan: "En la actualidad coexisten numerosos productos que se desenvuelven entre la ficción y la no ficción, sobreviviendo en la frontera de ambos términos" (Martínez \& Gómez, 2007: 125). Así, entretenido (mas no informado), enterado (mas no consciente), conectado (mas no vinculado), el sujeto contemporáneo figura ante los ojos de estos pensadores como un ser atrapado en narraciones estéticas (bien sean agradables o impactantes, pero siempre estéticas) (Gil Calvo, 2003) con pocas opciones de salir de la caverna en la que el poder político lo ha envuelto.

Asistimos, pues, a un mundo plano, pleno de religiones sin espiritualidad, trabajo sin laboriosidad, ciencia sin asombro, política sin política; un mundo, diríamos, vacío, donde "Cada uno exige estar solo, cada vez más solo y simultáneamente no se soporta a sí mismo" (Lipovetsky, 1986: 48).

\section{Integración estética}

Dice Luis Enrique Alonso (2005) que la perspectiva sociológica del estudio del consumo supera las perspectivas más utilitaristas del simple análi- 
sis del comportamiento adquisitivo. Vale aclarar frente a este concepto que no todo el análisis sociológico ha querido reconocer dimensiones no económicas en su manera de abordar el consumo. Sin embargo, como quedó claro al revisar los aportes de Baudrillard, hay elementos contundentes que muestran que, además de la dimensión económica, en el proceso del consumo participan asuntos que no están directamente relacionados con el precio de los productos. O mejor, que la sociedad de consumo establece una dinámica en la que incluso las variables concretas como el precio son codificadas socialmente como un símbolo e intercambiadas como tal. En esos códigos de circulación de bienes, y de asignación de valor simbólico, figuramos una clara participación de lo estético.

Dijo Umberto Eco (2000) que frente a las posiciones que los estudiosos establecen respecto a la cultura de masas, se podría establecer una categorización entre apocalípticos e integrados. Por un lado, hay unos autores que suscriben la idea de una separación entre arte superior y arte e inferior $y$, por el otro, una serie de estudios y estudiosos para quienes la cultura de masas trae cosas buenas y es digna de ser estudiada. No se trata de hacer una clasificación en la misma línea de Eco. Se trata, sí, de reconocer una postura diferente a la descrita anteriormente, donde el interés no se centra tanto en la calidad de los productos de la industria cultural como en los procesos de recepción social que los hacen asimilables y posibilitadores de sentido. En esta otra línea, si bien la estética tampoco es el centro de las reflexiones de los autores analizados, sí aparece en una perspectiva diferente, asociada comúnmente a lo popular, lo kitsch, y lo feo, categorías estéticas que se asumen como posibilitadoras de sentido.

Para comenzar esta reflexión, tomamos este apunte dilucidador de García Canclini (2009):

Una zona propicia para comprobar que el sentido común no coincide con el "buen sentido" es el consumo. En el lenguaje ordinario, consumir suele asociarse a gastos inútiles y compulsiones irracionales. Esta descalificación moral e intelectual se apoya en otros lugares comunes acerca de la omnipotencia de los medios masivos, que incitarían a las masas a abrazarse irreflexivamente sobre los bienes (p. 57). 
Allí advertimos el giro que se le ha dado a la cuestión. Ya no se trata del buen o el mal gusto, ni de la alienación de la que son "víctimas" los consumidores, ni del componente ideológico que atraviesan las producciones culturales. Todos esos elementos siguen ahí, pero en el paisaje. Se trata es de reconocer, desde el lado de la recepción, cómo son los procesos mediante los cuales se negocian los significados de los objetos.

Por esta razón se retoman, desde los estudios latinoamericanos, una serie de reconsideraciones importantes, donde lo emocional, lo popular, lo feo y lo melodramático -la cultura de masas en pleno-aparecen releídos a la luz de los potentes intercambios de sentido que impulsan en las sociedades a donde llegan. La crítica entonces que desde esta orilla del pensamiento se hace a los estudios eurocentristas apunta a que la aspiración racionalista había dejado por fuera aspectos vitales para el hombre, como las emociones. Por ello, más que como ruido, o como basura marginal, lo emocional se admite como objeto de estudio válido no solo para la psicología sino también para la comunicación, pues toda la comunicación, masiva o interpersonal, pasa por un componente emocional claro.

Cuando las teorías de la comunicación pervierten el significado del término "conciencia" identificando conciencia a cognición, como es práctica habitual desde los paradigmas meramente "informativos", y conciben los componentes valorativos y emotivos como sustancia extraña, como "ruido" ajeno a la "pura" comunicación, se incapacita ab inicio para comprender cualquier comunicación que pueda considerarse humana (Bericat, 1999: 228).

En esta línea teórica se asume que los contenidos de la industria cultural no por ser calculados conforme a la racionalidad económica dejan de ser susceptibles de ser analizados. En efecto, una de las ideas con más fuerza en este contexto de pensamiento sugiere que se necesitan unos procesos sociales y políticos que reconozcan las otras voces, la voz de lo popular que, lejos de lo feo que a veces resulta, recoge un sentir olvidado por la producción centralizada de información y contenidos.

No se puede perder de vista que uno de los parales de esta forma de entender la comunicación masificada está asentado en Latinoamérica. La 
denominada escuela latinoamericana integra voces de investigadores en el universo de los estudios sobre recepciones (Orozco), mediaciones (Martín-Barbero), hibridaciones (García Canclini) y un gran etcétera. En conjunto, estas propuestas tienen en común la idea de que del lado opuesto a la enunciación, a la producción del contenido, hay un sujeto activo que lejos está de ser un simple receptáculo de lo que el emisor unilateralmente ha producido. Hay una esfera válida, activa y llena de sentido del lado contrario. Allí, también se producen una serie de transacciones e intercambios donde los mensajes son reinterpretados, sujetos a varios procesos de apropiación, no solo comunicacional sino también social y política.

Los años setenta del siglo pasado motivaron muchos movimientos cuyo eje común fue la proclama de una libertad en la producción de información. El Sur, los pobres, las minorías, también tendrían derecho a producir su propia información y las propias narraciones sobre su devenir colectivo. Esta consigna, generalizada, fue llevando a un cambio en el eje del discurso, muy claro en el caso de Martín-Barbero, quien pasa de un libro titulado Comunicación, masa y poder a una propuesta teórica denominada $D e$ los medios a las mediaciones. Mientras en el primer libro se extiende en una acusación de la tiranía de la información como discurso ideológico predominante y unilateral, en el segundo hay una mirada que reconoce la complejidad de los procesos comunicacionales a los que se advocan los grupos sociales. Habría que entender entonces que ante la pantalla los sujetos no se encuentran como una tabula rasa. Aprile, ironizando al respecto, cita a John O’Toole: "Desearía que todos los consumidores fueran tan crédulos como la mayoría de los críticos de la publicidad” (Aprile, 1997: 21). En lo que interpretan las personas hay una historia social que recoge formas de ver el mundo, estrategias de vivir la cotidianidad y rituales que contienen formas de bailar, comer $y$, en general, de vivir la vida.

Sería muy pretencioso desconocer que quien se planta frente a la pantalla tiene una vida y es desde esa vida desde donde interpreta lo que la pantalla le propone. Esta nueva mirada permitió varios avances teóricos, metodológicos y hermenéuticos (en el sentido de nuevas formas de entender el objeto de estudio). Por un lado, la admisión de la recepción 
como una instancia activa del proceso de comunicación; por otro, la idea de que los productos culturales, más allá de si son o no arte, cultura alta o baja, son objeto de apropiaciones por parte de las personas, lo cual hace necesario comprender cómo se producen dichos procesos. Así lo propone García Canclini: "Para avanzar en esta línea es necesario situar los procesos comunicacionales en un encuadre conceptual más amplio que puede surgir de las teorías e investigaciones sobre el consumo. ¿Qué significa consumir? ¿Cuál es la racionalidad -para los productores y para los consumidores- de que se expanda y se renueve incesantemente el consumo?" (2005: 58).

A nuestra manera de ver, la estética aparece dotada aquí de una nueva forma, pues ya no queda en el simple lugar del señuelo, sino que alude a las sensibilidades desde las cuales se vive el proceso de comunicación. Al respecto, Monsiváis acota que la televisión le da forma a la subjetividad latinoamericana, pues "La televisión comercial: (forma) el orden nuevo de la vida latinoamericana” (Monsiváis, 2000: 231). En su estudio sobre el melodrama, el autor propone que nuestra educación sentimental se produjo, en Latinoamérica, por la vía de las radionovelas, el melodrama televisivo y la canción radial. Asumir esta afirmación es, para efectos de nuestro trabajo, pensar que más allá de la discusión del valor artístico de los productos de la industria cultural, el hecho de que estén ahí, moldeando las subjetividades y proponiendo formas de ver el mundo, implica asumir una cierta geografía humana conformada en el territorio de las subjetividades, surgida de un terreno de intercambio de significaciones: una geografía del sentido.

Mas, como vemos, esa negociación del significado de los productos culturales está atravesada enteramente por la estética, pues las personas lo que eligen es qué quieren sentir al momento de pensar en un canal u otro. Así lo manifiesta el melodrama, en el cual la gente quiere sentir que los pobres tienen una oportunidad y que el amor es una puerta de salvación a la vida. Se trata entonces de una elección de contenidos por la vía emocional.

Los boleros, los tangos, las melodías románticas más populares, todos los géneros de música juvenil -del ska, al rap- pueden devenir, más allá de su aparente trivialidad, auténticas cápsulas de 
sentido, módulos mínimos de experiencia humana donde cualquiera estará siempre en condiciones de encontrar un testimonio de su propia vivencia personal, puesto que en ellas se describen (Delgado, 1999: 56).

Así pues, surge la necesidad de repensar, al menos, dos categorías conceptuales para comprender la realidad desde esta nueva dimensión. Se trata de las categorías de consumo y recepción. Vistos desde una mirada amplia, a veces ambos conceptos se tratan por igual. La recepción es el proceso donde se consumen los contenidos, mientras que el consumo es un proceso de recepción y asimilación de objetos culturales y materiales. En el primer caso, la categoría consumo encuentra en los textos de García Canclini un espacio de resemantización.

\begin{abstract}
el consumo es el conjunto de procesos socioculturales en que se realizan la apropiación y los usos de los productos. Esta caracterización ayuda a ver los actos a través de los cuales consumimos como algo más que ejercicios de gustos, antojos y compras irreflexivas, según suponen los juicios moralistas, o actitudes individuales, tal como suelen explorarse en encuestas de mercado (Canclini 2005: 58-59).
\end{abstract}

En ese sentido, si "Consumir es participar en un escenario de disputas por aquello que la sociedad produce y por las maneras de usarlo" (García Canclini, 2005: 60), la tarea de los estudios apunta a reconocer en lo sensible algo posible en el marco de la investigación. Para ello se requiere la apertura a otros modos de razón, pues se precisa de una racionalidad que ayude a "reparar en los aspectos simbólicos y estéticos de la racionalidad consumidora" (p. 61), entendiendo que "La lógica que rige la apropiación de los bienes en tanto objetos de distinción no es la de la satisfacción de necesidades, sino la de la escasez de esos bienes y la imposibilidad de que otros los tengan" (p. 61). No se trata pues de un simple intercambio económico; participan en el proceso de consumo asuntos sensibles (la seducción con la que la publicidad se dirige a los consumidores, el imaginario que se desata en el futuro comprador, la forma como hace suyo el objeto y lo inserta en una cotidianidad privada de interacción con el objeto, a su vez que la forma como lo hace público y las estrategias que elige para portarlo). Sin tener presentes estos asuntos, se deriva de lo que afirma el autor, perderíamos de vista un importante medio de expresión humana. 
Esto se debe a que el gusto, tal y como nos lo enseñó Bordieu (2000), es un proceso histórico de aprendizaje social que recoge unas formas de ver el mundo, no desligadas de la clase social y los proyectos de vida de las personas. Y por esa razón, la influencia del primer mundo sobre el segundo sigue existiendo, pero ya no se entiende solo como dominación ideológica, sino como referente de la idea de mundo. Esta idea, desde luego, se presenta en los productos culturales extranjeros, que empiezan a calar en el imaginario: "Los latinoamericanos por críticos que sean memorizan demasiado del cine estadounidense: el sentido del ritmo, el uso de escenarios imponentes, los gags, la combinación justa de personajes principales y secundarios, la dosis de chantaje sentimental, las desembocaduras del final feliz, que en español también se llamará happy end" (Monsiváis, 2000: 57). Al final de su libro, Monsiváis remata: "Las instituciones del consumo y el gusto de Norteamérica, se vuelven las instituciones de gusto y de consumo en Latinoamérica: la ceremonia de entrega de los Oscar y de los Grammy" (2000: 223).

Ante la proliferación de productos culturales, y sentidos contenidos en ellos, algunos autores apuntan a una "espeleología" (Fernández Porta, 2008) del gusto; algo así como un enfoque de investigación donde se indague por las estructuras, las fórmulas y los recetarios ya famosos y reconocidos en la industria cultural. Por eso advertimos, dentro de la corriente de los estudiosos que se integran a la cultura popular, una corriente marcadamente política, donde hay una discusión del concepto de masa y una reivindicación del poder de lo popular, y una corriente que analiza más las codificaciones estéticas, asistidas por lo político o no, de la comunicación masificada, en productos como el cómic, la literatura de consumo, el cine y la música pop (Fernández Porta, 2008). En esta segunda línea, Fernández Porta, uno de sus contemporáneos exponentes, remarca:

Existir en estos tiempos implica actuar siempre en pleno minuto loco como si la suma de estos instantes fuera un tiempo de promisión religioso, o si se prefiere, ser un soldado de buzzer-beater (en términos de la NBA, el tiro que decide el partido en el último instante) sin

4 Acota Fernández Porta: 'Hubo un día no muy lejano, en el que al fetiche pop se lo llamaba 'simple', 'inmediato', 'superficial'. Esos atributos han sido desbordados por la emergencia de nuevos objetos y, con ellos, de nuevas formas de complejidad, que piden a gritos una lectura de segundo grado, si es que no la llevan incorporada” (2008: 9). 
dejar de comportarse de manera cívica y pía. Estos dos modos de temporalidad se justifican entre sí, el segundo legitima al primero, que a su vez es actualizado por el otro. Si solo viviéramos el segundo seríamos demasiado del pasado, si solo lo hiciéramos de lo primero, demasiado de hoy. Al asumir los dos combinados estamos listos para salir a la calle, comprar, competir y amar (p. 156).

En la cita del estudioso nos percatamos del doble interés que asiste a este tipo de estudios. Su categoría más defendida, el afterpop, insiste en que el consumidor contemporáneo, etiquetado como homo sampler, es decir, fragmento caleidoscópico de relatos y rituales de la cultura popular, no es el individuo masificado, sino un sujeto activo en eso de coleccionar retazos de historias, shows de televisión y noticias para fabricarse su propia identidad personal: lógica del patchwork. Pero este tipo de lecturas globales del sujeto contemporáneo va surgiendo de una lectura y un análisis profundo de los productos culturales que son consumidos por él. Así, se trata de un tipo de estudios que van del todo a la parte, donde la parte son los objetos (como lo hiciera Baudrillard), los relatos o las marcas, y el todo son las formas de vida que se van consolidando a través de los objetos de la industria cultural.

Por lo que respecta a nuestro interés, percibimos que en esta segunda línea de trabajo no hay necesariamente una adscripción ciega a los beneficios de la cultura de la información o de la sociedad de la comunicación masificada. Por el contrario, lo que vemos es que, en primer lugar, se da cabida en sus estudios a aspectos menos puristas y racionalistas de la vida (tales como las emociones, y categorías estéticas como lo feo, lo kitsch... ), y, en segundo, a través de la observación juiciosa de los intercambios de sentido que ocurren en las sociedades (hoy en día predominantemente virtuales y asociadas a la sociedad de consumo), se van logrando identificar unas tramas de intercambio de sentido claves en el mundo contemporáneo.

\section{Emergencias}

Más acá de la masa, y más allá de la discusión sobre el valor artístico de los contenidos de la era digital, aparecen para nosotros unas señales bastante claras en torno al lugar que se le ha dado a la estética en el contexto de la reflexión por la industria cultural. Lo primero es que la preocupación por la 
sociedad de consumo es uno de los más grandes espacios por donde se ha llegado a esta reflexión. La aplicación de la racionalidad técnica y los principios de la industrialización a la producción de contenidos (en apariencia) artísticos supone todo un foco de trabajo para bastantes autores. En segundo lugar, identificamos que en la mayoría de los casos la reflexión sobre qué es la estética y en qué dimensión debiera comprenderse no aparece en el foco de atención de los estudiosos. Se asume, de entrada: 1) o que la estética es la causante de que los mensajes sean más llamativos, placenteros, bonitos, cautivantes e impactantes, o 2) que todo lo que es popular, por el mero hecho de serlo, contiene una estética, que es de seguro una estética emergente y que como tal tiene derecho político a ser reconocida, si bien no desde la estética misma, sino desde la reivindicación política que esta supone en el contexto (popular) de su creación.

Por eso, terminamos este ejercicio de revisión con una mirada amplia a una serie de interrogantes que nos quedan y consignamos acá a manera de inventario para posteriores análisis.

Qué de estética hay en el aura. Como vimos, la distinción que hicieron Adorno y Horkheimer entre un arte superior y un arte inferior se basa en su concepción del arte (moderno) como una vía de liberación. Así, en la unicidad de la obra opera un cierto milagro que determina su recepción. Lo difícil que es llegar a la obra, su exclusividad, es parte del encanto que demarca esa distancia proxémica tan afín a la sacralización de las cosas. Allí lo estético está no solo en la obra, sino en la manera como se sacraliza su espacio de ausencia. Por el contrario, en la sociedad de masas, con la reproducción en serie - de la que Benjamin dijo que quitaba el aura a la obra-, más parece que el aura figura en función (y no a pesar) de la reproducción técnica. Uno de los argumentos con los cuales se nos venden algunos productos y contenidos es, precisamente, ese: que mucha otra gente ha leído tal libro, que muchos países han comprado tal serie, que muchas personas están usando o prefiriendo tal marca. Precisa Verdú: "En el capitalismo de ficción el paroxismo democrático (la reproducción de la democracia en falsas copias) ha llevado a la paradoja de que el aura de la obra de arte no proceda de su unicidad y fijación sino, por el contrario, de que se encuentre masivamente difundida" (2003: 88). 
Esto podría significar que mientras la masificación se supuso como un ruido que entorpecía la posibilidad de que una obra de arte expresara algo existencialmente necesario para la persona, hoy esa condición está supeditada a su masificación. Primero, porque si no se masifica, menos personas pueden conocer el contenido cultural; segundo, porque el número de personas que lo han conocido, difundido y compartido en sus redes entra a ser uno de los primeros garantes (es decir, ya no es solo la publicidad) de que el mencionado contenido cultural tiene algo para decir.

El concepto de masa puede suponer equívocos. Algo claro es que la idea de masa uniformiza todo lo que se pone en frente suyo. En la masa no cabe la individualidad ni la subjetividad. Recordemos que "Horkheimer y Adorno se ven llevados por la experiencia histórica de la que arrancaba su pensamiento a tomarse absolutamente en serio el diagnóstico weberiano: del proceso imparable de racionalización no se salva ninguna esfera, tampoco la esfera de la subjetividad” (Sánchez, 2009: 24). Dicho "desencantamiento del mundo" vendría a ser algo así como la causa de que el individuo se des-subjetivice y se entregue a la masa: "En la enigmática disposición de las masas técnicamente educadas a caer en el hechizo de cualquier despotismo, en su afinidad autodestructora con la paranoia populista: en todo este incomprendido absurdo se revela la debilidad de la comprensión teórica actual" (p. 53).

Vale aquí aclarar, como lo advirtiera Alonso (2001), que la idea de masa está vinculada a la idea de la reproducción social como un proceso mecánico. Nada más contradictorio con la realidad, si leemos la realidad en clave culturológica: una sociedad es un espacio de configuración de sentidos y construcción colectiva de lo que se entiende por mundo. Vale decir entonces que el aura no garantizaría por sí misma el surgimiento de un mundo con sentido. El aura opera como el garante de un proceso de racionalización extremo realizado por el artista, donde se toma el objeto artístico como una manifestación material de una mirada sobre el mundo. Una mirada, por lo general, crítica, aguda. Pero, al mismo tiempo, el mundo en el que ese objeto existe es un mundo que ya no es posible. No solo por las razones tecnológicas que han cambiado la comunicación para siempre, sino 
porque la experiencia subjetiva contemporánea poco espera que en su contacto con una obra de arte se despejen nuevos caminos de comprensión del mundo.

Descreer del concepto de masa llevaría a comprender que en las comunidades de sentido contemporáneas bien pueden surgir otras formas de configuración de esas auras, otros objetos que surgen a través de transacciones colectivas, incluso más que de la mente genial de un artista incomprendido. Entonces, tal vez no se trate de que el mundo esté agotado en su sentido, desencantado y vacío, tal vez "En realidad no hay 'nuevos mundos' que conquistar, sino nuevos lugares donde fundar el mundo conocido" (Yory, 2006: 47).

La estética como conexión. Por lo anterior parece válido preguntarse, de la mano de Adorno y Horkheimer, si fue en virtud del denunciado intento de dominio de la naturaleza, una de las principales pretensiones de la Ilustración, como se fue perdiendo sensibilidad frente al mundo, consciencia de la totalidad y una cierta mística frente a la naturaleza que llevaba a una esfera de respeto entre el hombre y ella. Sin duda, esa ruptura es una de las fisuras -luego irreparables- por donde se empezó a ver la estética solo como un asunto de superficie, y ya no como algo profundo, vinculado a la existencia misma del hombre, que en conceptos como cosmos había reflejado ese respeto y esa cierta distancia que surgía como consecuencia de sentirse parte de. Curiosamente, más adelante lo que va a denunciar Weber es que el mundo pierde encanto porque ya no vincula. $Y$ es que la Ilustración conllevó a una pérdida -dirán los críticos irreparableen términos de la desconexión del hombre con su origen, vía el desconocimiento de su participación en una totalidad. Así, mientras el cosmé tenía un sentido etimológico profundo, una serie de circunstancias históricas que cristalizaron en el proyecto ilustracionista llevó a la acepción de cosmética como algo superficial e, incluso, superfluo: "La caída del hombre actual bajo el dominio de la naturaleza es inseparable del progreso social” (Adorno \& Horkheimer, 1978: 54).

A través de las afirmaciones de la Dialéctica de la Ilustración, lo que vemos es un signo irreductible del tiempo en el que fue escrita, pero que hoy 
nos lleva a cuestionar, seriamente, si el ser fabricadas como objetos de consumo masificado, en sí mismo, puede llevar a que en las producciones de la industria cultural se aniquile completamente la posibilidad de producción de sentido. Lo que vemos es que, con un sentido profundo o superficial de lo estético, los productos masivos de la sociedad de consumo están allí, el arte masificado está allí y las masas están allí, conscientes o no, participando de unas comunidades que cada vez están más asociadas a dichos productos, y participando de una serie de procesos bastante transparente donde a las claras se pueden evidenciar unos procesos de intercambio de sentido. La crítica podría ser paralizante, y al serlo podríamos perder oportunidades de comprender, desde adentro, la lógica de configuración de identidades y deseo que se está realizando allí. Las marcas, cada vez más conscientes de ello, y, desde luego, obedeciendo a su lógica capitalista, son las que están marcando las pautas en las configuraciones de esas comunidades donde poco a poco el producto o el artista de moda son solo la excusa a partir de la cual comienzan a forjarse toda una serie de interacciones sociales que, a menudo, superan a la marca misma. Da qué pensar si la academia debiera quedarse solo en la denuncia o en la crítica acérrima que conlleva a la parálisis.

Sin embargo, en contraposición a esta pelea por la legitimidad de los productos de la industria cultural, lo que nos interesa es una estética, no nos importa si pura o no, como un asunto hermenéutico vital, vitalista, en términos de la posibilidad de ser en el mundo. Pero mientras en las miradas de los herederos del pensamiento crítico los mejores esfuerzos del aparato conceptual se dirigen a señalar peyorativamente los productos masificados por su carencia de un aura (Benjamin) o de alma (Lipovetsky), y en las miradas de los culturalistas los proyectos estéticos solo están ligados a una búsqueda de la identidad colectiva, nos sigue faltando un lugar donde podamos hablar de la estética como un proceso constitutivo y no como señuelo o como marca identitaria antropológicamente válida. Se advierte, de cierta manera, un cierto temor a la subjetividad, a la individualidad y al espacio íntimo en el que, si bien llegan las mediaciones, ocurren una serie de procesos que no están animados por la empancipación política de las clases, sino por una serie de cosas del individuo frente a sí mismo. Estos 
fenómenos, si bien podrían ser colectivos, hay que tratar de entenderlos, también, en la lógica individual, desposeídos de la búsqueda política. En ese temor a desprenderse de la mirada y las preguntas políticas, se advierte un claro legado de la escuela crítica, y un claro temor de que al deslindar la mirada política se esté apostillando, permitiendo, la conformidad con el hombre unidimensional.

Cuando Monsiváis afirma “Tener Historia así sea trágica, sobre todo si es trágica es señal de identidad. La historia absuelve y condena, y la gran clave para entenderla y fijarla en la memoria colectiva es el heroísmo, medio masivo de difusión de las repúblicas. La religión cívica del siglo XIX es la guía de los pueblos y el culto a la Historia” (2000: 80), no podemos menos que lamentar que el valor de lo sentimental esté tan referido al asunto identitario. La identidad, claro, está ahí; es necesario estudiarla. Pero también hay un enorme número de asuntos, como qué es lo que buscamos en esa naturaleza dramática o cómo es que logramos hacérnoslas con nuestro mundo a partir de dicha naturaleza, que en la pregunta por la identidad se disuelven. Esas preguntas serían, en su esencia, preguntas estéticas.

Insistimos, finalmente: da qué pensar si la academia debiera quedarse solo en la denuncia o en la crítica acérrima que conlleva a la parálisis.

\section{Referencias}

Alonso, L. (2005). La era del consumo. Madrid: Siglo XXI.

Alfagem. H. A. (2008-2009). Los paisajes del miedo americanos: la frontera México-Estados Unidos. Anuario de la Facultad de Ciencias Humanas, Universidad Nacional de la Pampa (Argentina), 9(8), 29-38.

Baudrillard, J. (2004). El sistema de los objetos. Buenos Aires: Siglo XXI.

Baudrillard, J. (1974). La sociedad de consumo. Sus mitos, sus estructuras. Barcelona: Plaza \& Janés. 
Bericat, E. (1999). El contenido emocional de la comunicación en la sociedad del riesgo. Microanálisis del discurso. Reis, 87, 221-253.

Debord, G. (1967). La sociedad del espectáculo. Valencia: Gallimard.

Delgado, M. (1999). El animal público. Barcelona: Anagrama.

Eco, U. (2005). Superhombre de masas. Barcelona: Lumen.

Enríquez,J. (2007). Entre el miedo y la distinción. El estado actual del fraccionamiento cerrado en las ciudades fronterizas de Tijuana, Nogales y Ciudad Juárez. Estudios fronterizos, 8(15), 9-49.

Fernández Porta, E. (2008). Homo sampler. Tiempo y consumo en la era after pop. Barcelona: Anagrama.

García Canclini, N. (2009). Consumidores y ciudadanos. Conflictos multiculturales de la globalización. México: Random House.

Hall, S. (1997). El espectáculo del otro. En Representation: Cultural Representations and Signifying Practices (419-444). Londres: Sage Publications. Recuperado de: http://www.ram-wan.net/restrepo/ hall/el\%20espectaculo\%20del\%20otro.pdf (Fecha de consulta: febrero 12, 2014).

Horkheimer, M. \& Adorno, T. ([1948] 2009). Dialéctica de la Ilustración. En Sánchez, J. J. (Ed.), Fragmentos filosóficos. Madrid: Trotta.

Horkheimer, M. \& Adorno, T. ([1947]1998). Dialéctica de la Ilustración. Madrid: Trotta.

Lipovetsky, G. (1986). La era del vacío. Barcelona: Anagrama.

Lipovetsky, G. (2007). La tercera mujer. Barcelona: Anagrama. Recuperado de: http://sinismos.files.wordpress.com/2013/02/109856484gilles-lipovetsky-la-tercera-mujer.pdf (Fecha de consulta: enero $15,2014)$. 
Lipovetsky, G. (2007). La felicidad paradójica. Ensayo sobre la sociedad de hiperconsumismo. Barcelona: Anagrama.

Lipovetsky, G. (2009). O Imperio do Efêmero. A moda e seu destino nas sociedades modernas. Sao Paulo: Companhia das letras.

Mafessoli, M. (2007). En el crisol de las apariencias. México: Siglo XXI.

Marina, J. (2007). Las arquitecturas del deseo. Una investigación sobre los placeres del espíritu. Barcelona: Anagrama.

Martínez, M. \& Gómez, A. (2007). Claves de la pervivencia del mito en los medios de comunicación. Información y Comunicación, 4, 124-137.

Monsiváis, C. (2000). Aires de familia. Barcelona: Anagrama.

Yory, C. (2006). Ciudad, consumo y globalización. Bogotá: Pontificia Universidad Javeriana. 